\title{
Rapid assay for the in vitro chemosensitivity testing of human breast tumours
}

Control of assay conditions and quality assurance

R.F.M. Oude Elferink, H.M.J. Goldschmidt, H.J. Majoor and J.F. Leijten

In this article, published in Pharm Weekbl [Sci] 1989;11(5):155-60, page 156, right-hand column, seventh paragraph, reads "(Mean/SD).100\%"; this should have been "(SD/Mean). 100\%".

\section{Supplement I}

On the front page of Supplement I "18th European Symposium on Clinical Pharmacy" [Pharm Weekbl [Sci] 1989:11(5)] it says that the 18th European Symposium on Clinical Pharmacy was "Organized by the American College of Clinical Pharmacy, the Dutch Society of Clinical Pharmacology and Biopharmacy and the WHO Collaborating Centre for Quality
Furthermore, the present address of R.F.M. Oude Elferink is Clinical Chemical Laboratory, Diakonessenhuis, Van Ketwich Verschuurlaan 82, 9721 SW Groningen, the Netherlands.
Control in Health Care". However, this should have been "Organized by the European Society of Clinical Pharmacy in co-operation with the American College of Clinical Pharmacy, the Dutch Society of Clinical Pharmacology and Biopharmacy and the WHO Collaborating Centre for Quality Control and Health Care". 